Article

\title{
Family Migration: Fulfilling the Gap between Law and Social Processes
}

\section{Laura Zanfrini}

Department of Sociology, Università Cattolica di Milano, Largo A. Gemelli, 1-20123 Milan, Italy; E-Mail: laura.zanfrini@unicatt.it; Tel.: +39-02-7234-2448; Fax: +39-02-7243-2552

Received: 21 June 2012; in revised form: 2 July 2012 / Accepted: 3 July 2012 /

Published: 5 July 2012

\begin{abstract}
In the last twenty-five years, the family entity has been imposed as a crucial actor in understanding migratory strategies and behaviors, the study of the integration into the host society, the analysis of the impact of migrations for the sending and receiving countries and, last but not least, the evaluation of migratory policies and practices. This article recalls the main theoretical prospects that put specific emphasis on family; identifies some "ideological traps" that frequently influence family immigration policies and practices; then develops some considerations about the advantages and disadvantages of family migration for both the sending and the receiving countries; finally, it devotes a specific analysis to the family reunification issue, describing how this right is ruled by the EU legislation. In the conclusion, the Author observes that, notwithstanding the fact that family constitutes a crucial actor in the process of human mobility, both the legislation and the receiving societies' expectations concerning migration continues to be founded on an individualistic conception. Among other consequences of this asymmetry, there is the fact that family reunion is not always the best solution if the well-being of all family members and the life chances of migrants' offspring are taken into account.
\end{abstract}

Keywords: migration studies; migrant families; migration policies; family reunification

\section{Introduction}

In the last twenty-five years, the family entity has gained a very important role, for both the extension of the research field of the migration studies and the rethinking of integration models [1]: the challenge is to adopt a new analytical perspective, represented by the family and its strategies to 
survive and develop, a fundamental decisional unit in the domain of migration choices, strategies, and behaviors.

According to contemporary theoretical perspectives, family is the decision-making unit or — at any rate - the institution on behalf of which the choice to emigrate is made and which "utilizes" its members for its needs of survival and development. Family is also the agency that receives and manages the precious flow of remittances coming from family members working abroad, determining its impact on the economies of the sending communities: in this sense, family is a strategic actor for the economic and social development of the countries of origin and can activate forms of co-operation and support, as well as processes of conflicting coercion and dynamics that may become causes or consequences of migration.

On the other side of the migratory process, family is a factor that strongly influences the evolution of the migratory project, supports (or slows down) the process of migrants' integration, and sometimes imposes a "generational sacrifice" in order to assure the best chances to the members of other generations. Moreover, from the standpoint of the receiving society, the presence of migrant families is surely a phenomenon that transforms the impact and significance of migration, translating an economic issue into a political one. Among other consequences of this gap, we have to take into consideration this paradox: family reunification is not always the best solution, because it could involve a deterioration of life chances of migrants' children and even of the relationship between various family members and generations. As we will see, the European experience is particularly emblematic on this point, because of its "schizophrenic" attempt to keep together the logic of the "gastarbeiter" (that is the migrant admitted with a temporary permit strictly linked to the working conditions) and that of the denizenship (a status accorded to the vast majority of migrants that guarantees the access to a rich range of rights and opportunities).

All this notwithstanding, family is a dimension generally undervalued in the legislation concerning immigration, which is founded on an individualistic perspective. In this regard, family is an emblematic example of the gap between social processes and their regulation, questioning our societies about the human and social costs of globalization, particularly with respect to the migrants' children's experience.

\section{The Emerging Role of Family in Migration Studies}

As noted, family has gained a progressively more important role in contemporary migration studies. In this section we will recall some of the main theoretical perspectives, in the field of socio-economic studies, focusing attention on family's strategies in their relation with migratory choices.

The new economics of migration [2], moving from a critique of the neo-classical paradigm and of its individualistic assumptions, redefines migration as a family strategy aiming at allocating human resources in order to face market collapse and inadequacy of welfare systems. As noted by D.S Massey and colleagues in their review of theories of international migration [3], a key insight of this new approach is that migration decisions are not made by isolated individual actors, but rather by larger units of related people - typically families or households - in which people act collectively not only to maximize expected income, but also to minimize risks and to loosen constraints associated with a variety of market failures (crop insurance markets, futures markets, capital markets) apart from those in the labor market. In fact, unlike individuals, households are in a position to control risks to their 
economic well-being by diversifying the allocation of household's resources, such as family labor. Moreover, in developing countries the institutional mechanisms (private insurances and governmental programs) for managing risks to household income are imperfect, absent, or inaccessible to poor families, giving them incentives to diversify risks through migration. Finally, the new economic theorists argue that families send workers abroad not only to improve income in absolute terms, but also to increase income relative to other households, in order to reduce their relative deprivation compared with some reference group (often constituted by families who have already sent some of their members abroad).

Nowadays, a very popular approach is network theory [4], which underlines the relational nature of migration and the various functions played by migrant networks, in particular in selecting which family member is the most suitable to migrate, and in supporting the process of adaptation to the new social context [5]. Migrant networks are sets of interpersonal ties connecting migrants, former migrants and non-migrants in origin and destination areas through ties of kinship, friendship, and shared community origin; therefore they constitute a crucial form of social capital. Being at the same time a network-creating and a net-dependent process, migratory movements acquire a self-propulsive dynamic. This means that, in a certain sense, they are more influenced by the system of family obligations and expectations than by economic or demographic variables, as supposed by the most popular theories until quite recently. Furthermore, every new migrant expanding the network reduces the risks of movement for all those to whom he or she is related, eventually making it virtually risk-free and costless to diversify household labor allocations through emigration. As a consequence, as networks expand and the costs and risks of migration fall, the flow becomes less selective in socioeconomic terms and more representative of the sending community; for example, registering the presence of individuals of different age and gender. Lastly, once they have begun, flows can become very difficult to be controlled by governments, because the process of network formation lies largely outside their control; certain immigration policies, however, such as those intended to promote family reunification, work at cross-purposes with the management of migration flows, since they reinforce migrant networks by giving members of kin networks special rights of entry.

A rich array of contributions come from gender studies, whose main merit is that of having recognized the gendered nature of migratory models, behaviors and institutions, as can be brought to light by focusing attention on family and its system of labor division [6]. For example, some scholars have studied how, following the migration of one, some or all family members, the relationship between men and women changes and evolves, according to specific "cultures of migration" that assign different tasks and responsibilities to the various components of the family, not necessarily in coherence with the traditional role models. Others have emphasized the special significance of women's experience [7], the possibility of emancipation connected with the migration, but also the subjection of individual projects to the need of the nuclear or of the extended family [8]. Furthermore, a chief outcome of the research about female migrations concerns the close relationship linking them with the various welfare regimes and their current problems [9], as well as with the scant development of welfare policies in a lot of sending countries [10]. Finally, a special stress has been placed on the "care-drain" process caused by the migration of wives and mothers, and on the various forms of "transnational motherhood" activated to continue taking on the responsibility of caring despite 
physical distance. In this context, a main concern regards the phenomena of left-behind children, an expression which has been significantly coined to allude to mothers' migration, not to the fathers [11].

Another idea worth mentioning is that of welfare magnet effect [12], emphasizing the role of welfare benefits in the genesis, directionality, and evolution of migratory movements. The magnet hypothesis has several facets. Welfare programs can attract immigrants who otherwise would not have migrated to a certain destination; but they can also discourage immigrants who "fail" to return to their sending country. Actually, being a self-selective population who have chosen to incur the costs of migration, immigrants are more sensitive to the offer of welfare benefits than the native population; they are more inclined to geographical mobility with the consequence that inter-territorial differences in welfare benefits generate magnetic effects on the immigrant population. Besides the potential policy significance of these considerations, it is important to note that what guides the decisions about mobility and settlement is the family wellbeing, whose importance could even overcome, in certain circumstances, that of working opportunities for the family breadwinner.

Other important insights have been coming from the concept of transnationalism, a label which has become very popular among migration scholars. As a matter of fact, international migrations are commonly considered as one of the major social processes through which the globalization breaks into the various social institutions and structures, unhinging old approaches soaked in "methodological nationalism" [13]. In this framework, the idea of transnational family [14] not only overcomes methodological nationalism in the analysis of the processes of integration, but also offers a really good example of the persistence of transnational belonging and practices along with the passing of generations [15]. At the same time, it reveals the salience of the feedback effects that migration produces in the source community, even after various generations [16].

Last but not least, the philosophy of co-development [17] enhances the roles of migrants, diasporas and transnational families for the economic and social development of the communities of origin. We will speak about this in the next section.

\section{The "Pros" and "Cons" of Family Immigration}

As for the relationship between family and migration, a central issue is represented by the "pros" and "cons" of the migrant family's reunification for both the sending and the receiving countries.

Starting from the latter-i.e., the receiving countries - we can observe that the presence of families is usually considered as a factor of "normalization" and social acceptance of migrants. The same conditions required by the law to obtain reunification with their family members [cf. § 5] press migrants to emerge from the informal economy and, if it be the case, from illegality, and to achieve better living conditions. In some legislation, the possibility to migrate with one's spouse and children is conceived as a means to attract "desired" migrants, such as high-qualified workers or potential investors, and encourage them settling down. For the receiving nations, especially in the case of societies confronted with a serious ageing concern — as is the norm in contemporary Europe-the arrival of migrant families is also considered as a way to sustain the population growth and the renewal of the active-age population and labor forces [18]. At the same time, this reinforces cultural pluralism, a trait that enjoys a positive consideration by significant stakeholders in contemporary societies. Lastly, family immigration favors - and legitimizes - the development of social research and social 
work applied to the (real or socially constructed) "problems" of migrants and their descendants, and fuels the survival strategies of certain organizations facing the loss of autochthonous clients (for example vocational schools).

Obviously, from the point of view of the host countries family immigration has also various harmful consequences. In general, favoring the process of permanent immigration, it impedes the possibility to modulate migrants' influx and presence in accordance with the labor demand, a possibility particularly stressed in the European context. In fact, it was exactly the growing presence of labor migrants' family members that, in the 1970's, changed immigration from an economic issue into a political one, with the emergence of all the questions related to intercultural and inter-religious cohabitation. In the eyes of the local population, family immigration increases the strain of migrants' presence on the welfare apparatus (public schools, health, assistance, etc.), encouraging competition with the weaker sectors of the autochthonous population for access to social services and benefits (crèches, subsidized housing, etc.). This is especially true where immigration is "poor", as in the case of the contemporary European landscape: it is sufficient to note that one out of ten people at risk of exclusion, has a migrant background in the European Union. On average, 26\% of non-EU migrants and 19\% of EU migrants are at risk of poverty, compared to $17 \%$ of the "local" population [19]. After all, family immigration irreversibly changes the hereditary characters of native people, bringing into question the idea of a nation founded on the principle of descendent; again, an idea particularly rooted in the European legacy. If, as observed, family immigration enriches a society bringing with it other cultural traditions, at the same time it forces the native population to come to terms with cultural and religious pluralism and with its "hottest" questions, most of which involving above all family and family life (see, for instance, arranged, forced and polygamous marriage; crimes of passion; genital mutilation and so on).

On the sending countries' side, researchers' attention has been predominantly given to the "cons" of family immigration. This is due to a very pragmatic reason: the departure of a migrant worker's family members produces the immediate effect of slowing down or stopping the flow of remittances. At the same time, it discourages investments and returning migration. Considering the dramatic importance of migrants' remittances and investments for many source countries, we can understand how these may try to discourage family reunifications in a more or less open manner. According to some researchers' results, family immigration could also have the effect of weakening the process of accumulation of human capital, as it "worsens" the school performance of migrants' children. For example, a transnational research project focused on the Filipinos migrants' children [20] permitted the author and some colleagues to register different school's career paths. Left behind children experienced a process of distortion of their educational and professional aspirations, due to the hegemony exerted by a strong "culture of migration", but at the same time they could benefit from the opportunity to attend high quality schools and universities, thanks to the remittances coming from their parents working abroad. Aware of the enormous sacrifices and efforts of their parents, they tried to do their best and had educational and working ambitions that are higher than their peers. In contrast, those who had rejoined their parents in Italy during their childhood were subjected to a high risk of dropout and unsuccessful records at school, due to both linguistic barriers and the need to work and gain money. Finally, migrants' children who had arrived in Italy at a mature age, even if well educated, were largely involved in a brain wasting process. 
Although all these results could lead us to think that, for the sending societies, family reunification abroad produces almost only negative consequences, we can try to identify also some "pros" of family emigration. Family emigration slows population growth and pressure on the school system, an impact that can be envisaged by those countries which experience dramatic demographic increases and lack resources to guarantee education, health and social assistance to the young generations. In this perspective, children and youth emigration can constitute a "safety valve" for unemployment, in the face of a decidedly considerable growth rate that outpaces the capacity to generate new jobs. Again, family emigration increases the number of citizens who reside abroad, an outcome that could be envisaged by those States interested in the prospect of diaspora's mobilization as a strategy to support the economic and social development of the sending communities [21]. Traditionally the idea of migrants as agents of development of their origin countries referred mainly to temporary migrants oriented to return home. Attention has now shifted to a more complex picture of the diasporas to include permanent expatriates, subjects well integrated in host countries and second-generation immigrants [22]. Last but not least, even if, as we shall see, it is not always the best solution, family reunification is expected to contain the social costs associated with human mobility. From this standpoint, it should be welcomed, despite the computation of its burdens and benefits.

\section{The "Ideological Traps"}

The discourse about the relationship between family and migration is often the victim of what we call "ideological traps" [23]: filters across which we look at the reality and we estimate the outcomes of various phenomena and behaviors. As we shall see, a consequence stemming from this can be the legitimization of migration policies and practices producing high human and social costs for the individuals and families involved, influencing the same choices about family reunification.

The first trap is that of economic liberalism, expressed by the tendency to socially and institutionally construct migrants as pure workers-labor force or, according to the current migration policies, high-qualified workers or "brains" useful to enforce economic competitiveness-atomistic actors without familial ties and links. Emblematically embedded in the figure of the "guest worker", this conception is witnessed by the various schemes through which the receiving states try to prevent migrants' settlement and reunification with their family members; i.e., schemes for seasonal migrations, rotation schemes, and so on. In any case, this conception is paradoxically - and maybe unconsciously - supported also by those political and civil society's actors more sympathetic with migrants, whenever they attempt to legitimize migrants' presence by stressing their economic role and the "need" of their work ("those that have a job can come, and, more precisely, a job we do not want to carry out"). In such a way, the idea promoted is that the governing of human mobility must obey economic considerations, and the arrival of the family members is seen as an unwelcome and useless consequence of the importation of labor. Especially during a phase of economic recession, as is presently the case, it becomes more and more difficult to justify the presence of migrants and their families, and in particular to justify their costs in terms of public welfare. At any rate, some countries do not hesitate to adopt this doctrine in a resolute way, inhibiting family reunification even to the exclusion of pregnant partners. 
A second trap can be defined in terms of functionalistic familism: the emphasis is put on the idea of migration as a family mandate, which can justify the sacrifice of the individual projects and aspirations, whenever the cultural codes and traditions expect their subjugation for the collective (familial) wellbeing. This approach is oriented to defend the traditional division of labor based on gender, assigning the father the role of the main breadwinner, even if this implies his emigration. In this prospect, the problem lies exactly in what does not appear to be a problem: the tendency to consider the father's absence as "normal" and the experience of growing up in families with only one parent (the mother), and its consequences concerning the process of intergenerational transmission of marital and parental roles [24]. As denounced by some researchers in the sending countries, this conception involves an asymmetric evaluation of separated families: if the departure of the father is accepted or even socially appreciated, because it is coherent with traditional role expectations, the mother's emigration is considered as inconvenient and in contrast with the wellbeing of children and other family members. In this case, families where the mother is working abroad, instead of being supported, risk facing isolation and social stigmatization. Even in the eventuality of family reunification, children may continue to accuse their mothers for having "abandoned" them, feeding the mother's sense of guilty.

Another risk is involved in the adoption of the filter of feminism, the third ideological trap. In this case, migration is primarily considered as an opportunity of emancipation for women-especially when this entails leaving a patriarchal society_or as a source of exploitation for female migrants. In this vein, a "degendarization" of society is desired [25] in order to promote the advent of more balanced models of division of labor, permitting both mothers and fathers not only to be active in the labor market but also to have a part in their children's education and care, thanks to a practice of interchangeable roles. Actually, even when sharing this perspective-as it stresses the opportunity to design a society where the gender will matter less - we cannot ignore that, with the aim to surmount the conventional conception of the family and especially of motherhood, it risks treating the cost of separation as merely being a traditionalist construct. Consequently we may assist to the inhibiting of any initiatives aimed to limit the migration of mothers or to offer them a special support.

The last ideological trap is cultural differentialism, by which we mean the legitimization of special rights (e.g., the so-called "ethnic rights") and behaviors even if they contrast with the cultural codes of the receiving society. Immigrant societies fall in this kind of risk category to the extent to which they admit practices incompatible with their legal culture - or also with their common sense of what is dangerous or proper conduct - presuming that these practices are based on different cultural traditions that must be accepted and recognized. In the past, the evocation of presumed cultural specificities was used to justify deplorable measures aimed, for example, to select potential migrants (as in the cases of Indian girlfriends subjected to virginity testing before obtaining the permit to rejoin their future husband). However, beyond these extreme examples, a differentialist approach can induce public authorities to be "tolerant" towards certain kinds of conduct, as in the case of men who use violence against their wives and children. Finally, differentialism is a danger lurking, in that, as stressed by the contemporary debate about multiculturalism, it is particularly detrimental to the most vulnerable members of the family, whenever the respect of the minorities' cultures overcomes the safeguard of individual rights and dignity. 


\section{Concerning the Right of Family Reunification: The European Experience}

In the European experience, in contrast to what happens in the so-called "settlement countries" (Australia, Canada, New Zealand, United States), family migration was an unexpected-and "undesired" - phenomenon, to a certain extent induced by the policies of immigration control that have been in force since the 1970s. In any case, in many countries this has become the main channel of entry. As a matter of fact, despite attempts to avoid the permanent settlement of migrants and their communities, family reunification is now considered as a fundamental right, dependent upon a certain level of income and integration.

In the Member States of the European Union, according to the Council Directive 2003/86 the absolute right to residence must be recognized to: $a$ ) the sponsor's [26] spouse; $b$ ) the minor children of the sponsor and of his/her spouse, including adopted children; $c$ ) the minor children including adopted children of the sponsor where the sponsor has custody and the children are dependent on him or her [27]; $d$ ) the minor children including adopted children of the spouse where the spouse has custody and the children are dependent on him or her [28]. In accordance with the same Directive, the following subjects may have the right to residence: $a$ ) first degree relatives in the direct ascending line of the sponsor or his/her spouse, where they are dependent on them and do not enjoy proper family support in the country of origin; $b$ ) the adult unmarried children of the sponsor or his/her spouse, where they are objectively unable to provide for their own needs on account of their state of health; c) the unmarried partner with whom the sponsor is in a duly attested stable long-term relationship and his/her children. Finally, further spouses apart from the one already residing in the country in the event of a polygamous marriage do not have the right to residence: in this specific case, the EU legislation put a strict fence to the possibility of accepting an institution contrary to the European legal culture.

Above and beyond the variety of the national rules - which must be coherent with the previous statements - we can observe that the right to family reunification is based, first of all, on the relationship of dependency between the applicant and the family member s/he is joining. This provision has the consequence of ignoring — or sometimes, especially in the past, even impeding - the participation of the reunited family members in the labor market. More crucially, it compromises the fate of the children when they became of age: if they lack the prerequisites for obtaining the renewal of their permit (for example a job contract or attendance in the educational system), they risk, according to some legislations, to be forcibly deported (considering that they cannot formally obtain a permit for family reasons once they become of age). In any case, these provisions reflect a "legal" concept of the family with the consequence of disregarding the different definitions of kinship shared in some cultures of origin [29], but also those arisen from the new confines of the family resulting from migration itself (e.g., the care giver of the children left behind), or even those shared by the host country (e.g., children of age that, in most European societies, continue to be dependent on their parents and to live with them) [30].

Aside from the relationship of dependency, there are two other criteria that contribute to make the right to family reunification a selective right. The first one is the status of the applicant: temporary migrants, permanent migrants, EU citizens, citizens allowed free circulation in the EU, naturalized citizens enjoy different opportunities and rights, even possibly being completely excluded from this possibility (as usually happens to seasonal migrants and to other categories of migrants defined as 
"temporary" [31]). The second criterion concerns the level of integration. All national legislations define requisites that the migrant must possess in order to apply for the entry of their family members (accommodation, income, sickness insurance, etc.). Nevertheless, in recent times, we observed the tendency to require a certain level of integration also for the family member who is joining (this requisite is generally assessed by language tests or reached by the attendance of mandatory courses). All things considered, the interweaving of these criteria gives rise to a selective access to the right to join one's family, introducing discriminations on the basis of citizenship, legal status, socio-cultural conditions and gender. The more a migrant is poor and vulnerable, the less s/he can benefit from this right. Needless to say, we are alluding to fundamental human rights.

Actually, policies for family immigration can be seen as an emblematic example of a persistent tension, strongly embedded in the European history, between the logic of the guest worker-the illusion to select entrants and residents according to the labor market needs and to the economic gain of the host society — and the logic of denizenship: the progressive extension of migrants' prerogatives, claimed by the European tradition of respect of human rights [32]. Here we come to what I call the unresolved paradox of the European experience [33]; that is the paradox of a population of (temporary) workers transformed into denizens, without any significant change in the expectations of Europeans concerning immigration. In fact, those that on one hand are recognized as universalistic rights, to which migrants are eligible in conditions of equality with citizens (for example, the right to a job or to housing) are, at the same time, necessary requisites for obtaining the status of regular migrants - exactly the same status that confers the possession of rights — and in particular for acceding to the right of family reunification.

\section{Conclusion: Is Family Reunion Always the Best Solution?}

Family immigration produces a series of costs and benefits for both the sending and the receiving countries; costs and benefits not always adequately appraised by researchers and policy makers, both conditioned by an individualistic conception. At the same time, the legislation in force in the European context, while considering the reunion of the family as a fundamental right, presents a set of limits that makes this right selective based on the juridical and socio-economic status of the migrant. Besides all these considerations, however, one question arises: is family reunification always the best solution when the well-being of all family's members and the life chances of migrants' offspring are taken into account? Or, contrarily, does the gap between the crucial role played by the family in the process of human mobility and the migration's conception on which both the legislation and the receiving societies' expectations are based, make the reunification an unsatisfactory solution?

Empirical evidence provides contradictory findings, which, in any case, can be helpful for reflection. Reunification with family members, particularly children, is especially envisaged by those migrants who possess a "weak" status, which prevents them from maintaining the links with the country of origin (for example because of the geographical distance, or of the lack of proper documents). Paradoxically, a "strong" status (e.g., to be a EU citizen living in another European country) may discourage reunification (as often happens to Romanians working in Italy) or favor a sort of physical and symbolic commuting with the sending country that could be detrimental to young children and their school careers (Italians living in Germany are a case in point [34]). Migrant parents 
often reunite their children even if they lack the best conditions and the time for taking care of them, to the point that difficulties encountered can lead them to send the children home again to be raised by their relatives (the same sometimes happens to children born in the host country). Reunification is thus not necessarily permanent, since migratory movements must adapt to work commitments, to family strategies and even to the desire of preserving the attachment to the country of origin. More often, reunification involves children who are on the verge of reaching the age of majority (that is the limit age to rejoin parents through the procedure of family reunification), giving life to the so-called "spurious" second generations who frequently encounter difficulties of integration in the new society. When they lack one or more of the prerequisites prescribed by the law, migrants can resolve to realize a "de facto" reunification, sponsoring the arrival of the spouse or/and the children who will not have a permit of stay, staking a claim on their life chances. In this latter case, a possible outcome is the formation of a "mixed status family", whose members enjoy different legal conditions and diverse life opportunities. After all, as we have noted in describing the pros and cons of family immigration, family reunification does not seem to be the best solution if we consider, for example, the school assessments of migrants' children.

At any rate, legislation merits a special attention. Not only because, as we have seen, even in democratic and progressive Europe the right to family reunification is accessible only to certain immigrants with a tendency to exclude the poorest and the weakest, But also because the relationship between family's strategies and legislative restrictions often generates "perverse" outcomes, augmenting the vulnerability of the individuals involved. Actually, going beyond the question of family reunification, it is important to note that the blurry relationship between family and migration laws is characterized by tensions and contradictions. On the one side, being the outcome of a weighing up of many and varied interests - among which the slowing down of immigration and its settlement, the containment of its costs, the defense of the nation's identity, the need to facilitate migrants' integration - the regulation in force inevitably produces "imperfect" solutions. On the other side, as stressed by a set of contemporary theoretical streams [cf. § 2], the structure of networks, needs and obligations organized around the family constitutes a real challenge to the systems of migration control and management of both the receiving and the sending countries. Notwithstanding the fact that family constitutes a crucial actor in the process of human mobility, the legislation concerning migration (but the same could be demonstrated as regards the domain of citizenship) continues to be founded on an individualistic conception. If we wish to contain the costs of migrations and at the same time amplify their benefits for individuals, families and the countries involved, fulfilling this gap is essential.

\section{References and Notes}

1. Zanfrini, L. Dai "lavoratori ospiti" alle famiglie transnazionali. Com'è cambiato il "posto" della famiglia nei migration studies. In La migrazione come evento familiare; Scabini, E., Rossi, G., Eds.; Vita \& Pensiero: Milano, Italy, 2009; pp. 167-192.

2. Stark, O.; Bloom, D. The new economics of labor migration. Am. Econ. Rev. 1985, 75, 173-178.

3. Massey, D.S.; Arango, J.; Hugo, G.; Kouaouci, A.; Pellegrino, A.; Taylor, E. Theories of International Migration: A Review and Appraisal. Popul. Dev. Rev. 1993, 3, 431-466. 
4. Boyd, M. Family and Personal Networks in International Migration: Recent Developments and New Agendas. Int. Migrat. Rev. 1989, 3, 638-670.

5. Fawcett, J.T. Networks, Linkages and Migration Systems. Int. Migrat. Rev. 1989, 3, 671-680.

6. Pessar, P.R. The Role of Gender, Households, and Social Networks in the Migration Process: A Review and Appraisal. In The Handbook of International Migration: The American Experience; Hirschman, C., Kasinitz; P., DeWind, J., Eds.; Russell Sage Foundation: New York, NY, USA, 1999.

7. Kofman, E. Female "Birds of Passage" a Decade Later: Gender and Immigration in European Union. Int. Migrat. Rev. 1999, 2, 269-299.

8. Morokvasic, M. Women in Migration: Beyond the Reductionist Outlook. In One-Way Ticket: Migration and Female Labour; Phizacklea, A., Ed.; Routledge and Kegan Paul: London, UK, 1983; pp. 13-31.

9. Esping-Andersen, G. Social Foundations of Postindustrial Economies; Oxford University Press: Oxford, UK, 1999.

10. Ehrenreich, B.; Russel Hochschild, A. Global Women. Nannies, Maids, and Sex Workers in the New Economy; Henry Holt \& Company, Metropolitan Books: New York, NY, USA, 2003.

11. Zanfrini, L. Braccia, menti e cuori migranti. La nuova divisione internazionale del lavoro riproduttivo. In La rivoluzione incompiuta Il lavoro delle donne tra retorica della femminilità e nuove disuguaglianze; Zanfrini, L., Ed.; Edizioni Lavoro: Roma, Italy, 2005; pp. 239-283.

12. Borjas, G.J. Immigration and Welfare Magnets. J. Labor Econ. 1999, 4, Part 1, 607-637.

13. Wimmer, A.; Glick Schiller, N. Methodological Nationalism, the Social Sciences, and the Study of Migration: An Essay in Historical Epistemology. Int. Migrat. Rev. 2003, 3, 576-610.

14. Bryceson, D., Vuorela, U., Eds. The Transnational Family. New European Frontiers and Global Networks; Berg: Oxford, UK, 2002.

15. Foner, N. The Immigrant Family: Cultural Legacies and Cultural Changes. Int. Migrat. Rev. 1997, 2, 961-975.

16. Zanfrini, L. Sociologia delle migrazioni; Laterza: Roma-Bari, Italy, 2007.

17. European Parliament resolution on development and migration [2005/2244 (INI)].

18. In Europe, this argument has been particularly emphasized since the publication of a report realized the Union Nations Secretariat. Cf. ONU-Population Division, Department of Economic and Social Affairs, United Nations Secretariat, Replacement Migration. Is it a Solution to Declining and Ageing Populations? ESA/P/WP. 160, 21 March 2000.

19. Social Situation Observatory. Detailed Analysis of the Relative Position of Migrants; Research Note 1/2010. Available online: http://www.socialsituation.eu/research-notes/RN01_2010_ Migrants.pdf/?searchterm=Detailed analysis of the relative position of migrants (accessed on 27 June 2012).

20. Zanfrini, L., Asis, M., Eds. Orgoglio e pregiudizio. Una ricerca tra Filippine e Italia sulla transizione all'età attiva dei figli di emigrati e dei figli di immigrati; FrancoAngeli: Milano, Italy, 2006.

21. A good example of this perspective, with a special focus on the families and children's needs, is represented by the transnational Mapid project; please refer to the final report: Baggio, F., Ed. 
Brick by Brick. Building Cooperation between the Philippines and Migrants' Associations in Italy and Spain; Scalabrini Migration Center: Manila, Philippines, 2010.

22. In fact, thanks in particular to their knowledge of the opportunities, the distribution channels and the market prospects, to their bilingualism, and to the information at their disposal about the customs and the laws of the countries involved, members of the Diasporas can give great impetus to commercial flow, investments and the creation of businesses, the transfer of new technologies, the circulation of expertise and cultural cross fertilization.

23. Zanfrini, L. La migrazione come processo familiare. Studi Emigrazione. Int. J. Migrat. Stud. 2011, 184, 769-782.

24. SCM (Scalabrini Migration Center). Hearts Apart. Migration in the Eyes of Filipino Children; Episcopal Commission for the Pastoral Care of Migrants-Overseas Workers Welfare Administration: Manila, Philippines, 2004.

25. Parrenas, R.S. Servants of Globalization. Women, Migration and Domestic Work; Stanford University Press: Stanford, CA, USA, 2001.

26. For the purposes of this Directive "sponsor" means a third country national residing lawfully in a Member State and applying or whose family members apply for family reunification to be joined with him/her.

27. Member States may authorise the reunification of children of whom custody is shared, provided the other party sharing custody has given his or her agreement.

28. See previous note.

29. Valtolina, G.G. Il parenting: modelli e tradizioni culturali a confronto. Studi Emigrazione. Int. J. Migrat. Stud. 2011, 184, 805-823.

30. Valtolina, G.G., Ed. Una scuola aperta al mondo. Genitori italiani e stranieri nelle scuole dell'infanzia a Milano; FrancoAngeli: Milano, Italy, 2009.

31. According to the EU Directive, Member States may require the sponsor to have stayed lawfully in their territory for a period not exceeding two years, before having his/her family members join him/her.

32. Zanfrini, L. Cittadinanze. Appartenenza e diritti nella società dell'immigrazione; Laterza: Roma-Bari, Italy, 2007.

33. Zanfrini, L. I “confini” della cittadinanza. Perché l'immigrazione disturba. Sociologia del Lavoro, 2010, 117, 40-56.

34. Colasanto, M., Zanfrini, L., Eds. Famiglie sotto esame. Una ricerca sull'immigrazione italiana in Germania e l'esperienza scolastica delle nuove generazioni; Vita \& Pensiero: Milano, Italy, 2009.

(C) 2012 by the author; licensee MDPI, Basel, Switzerland. This article is an open access article distributed under the terms and conditions of the Creative Commons Attribution license (http://creativecommons.org/licenses/by/3.0/). 